\title{
Superconductivity devices are headed into space
}

Washington. Only six years after the discovery of a new generation of high-temperature (high- $T_{c}$ ) superconductors, devices made from the materials are scheduled to be tested in space for the first time.

The US Naval Research Laboratory (NRL) will have the chance to launch two High Temperature Superconducting Space Experiments (HTSSE) - one in 1993 and the second in 1996. The goal is to "speed up the transition between basic research and system applications", says George Price, project manager at NRL for the space experiments.

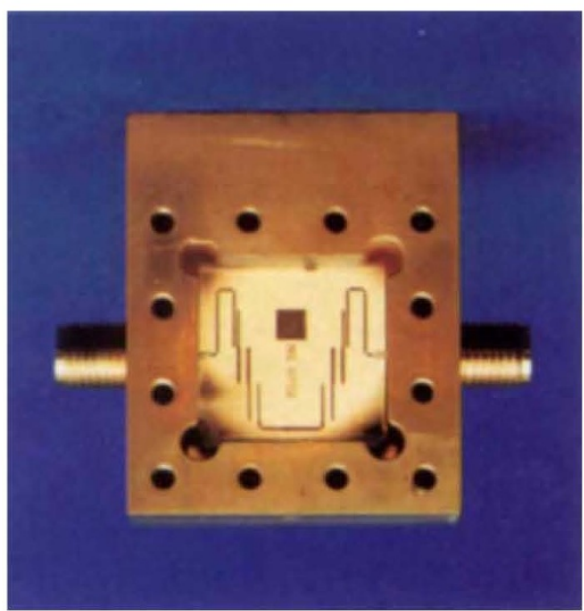

A space-bound, high-T, filter

Each mission, costing $\$ 20-\$ 25$ million, will be launched into Earth orbit as part of the payload on a US military satellite. HTSSE 1 will carry 15 relatively simple devices, most of them filters used in communications satellites to select specific microwave frequencies from the incoming radio noise. The superconducting filters, on average, are ten times more discriminating than similar filters made of metal.

Researchers hope that the improved efficiency and lower energy losses from using high-T materials on satellites will lead to smaller yet more powerful computers, antennas and other subsystems. With weight at a premium on any launch, says James Ritter, who manages the NRL programme that is funding the experiments, "we've always believed that the key payoffs from superconductivity would come from space".

Improved performance lies at the heart of the HTSSE programme. In January 1989, NRL sent out an invitation that, by the standards of the defence industry, was remarkably broad and open-ended. The agency was interested in funding, and flying, any kind of device that used the new high- temperature superconducting materials. The only requirements were that the device should improve existing performance by at least an order of magnitude, and that it could be reproduced (NRL asked for five copies).

"We thought that was a tremendous challenge to industry", says Ritter. Despite the fact that laboratories around the world were still discovering superconducting materials, the invitation attracted proposals from 35 organizations, including established companies such as Hughes Research Laboratory, American Telephone and Telegraph (AT\&T) and Space Systems Loral and such start-ups as Superconducting Technology, Inc., of Santa Barbara, California, and the University of Wuppertal in Germany. All but two of the 15 devices on HTSSE 1 are made of YBCO (yttrium-barium-copperoxide) superconducting thin films on various kinds of substrates.

The HTSSE 1 experiment will evaluate the performance of each device in space and how it is affected by radiation. A cooling system on board will maintain an operating temperature of 70-75K. HTSSE 2 will have more ambitious goals, including the testing of entire satellite subsystems that use superconducting components. It will also include communications tests from Earth to orbit.

Eventually, high-T superconductors may even make possible new kinds of spacecraft instruments, such as multispectral sensors that in a single device can detect radiation ranging from microwave to ultraviolet energies. Such a sensor could be placed on a space probe to the outer planets, where the ambient temperature is below the transition temperature of the new superconducting materials.

HTSSE is the US government's most visible effort to apply the discovery of hightemperature superconducting materials, but research is also being sponsored by the Defense Advanced Research Projects Agency (DARPA), the Strategic Defense Initiative and elsewhere. DARPA alone will spend $\$ 36$ million this year on high- $T_{c}$ research, only a fraction of which is related to space applications. Knowledge and hardware from these projects will increase the value of the NRL experiments "by at least a factor of five", says Ritter.

Ritter hopes that successful HTSSE missions will lead to additional experiments. In the meantime, says David Chaffee of the trade newsletter Superconductor Week, HTSSE has given some focus to the budding superconducting market. "At a time when it seemed like things were going to be stuck in research forever", says Chaffee, "HTSSE provides a means to look beyond that".

Tony Reichhardt

\section{NSF unmoved by politics of relocation}

Washington. A forced shift towards supporting industrial research (see page 611) is not the only move the National Science Foundation (NSF) is contemplating. The site of the agency's headquarters has become a political football, and a congressional committee has launched an investigation into the circumstances behind a decision to move the agency from the District of Columbia to a new building a few miles away in suburban Virginia.

For several years, NSF has been scheduled to move from its cramped and shabby - but well-situated _- office building three blocks from the White House. Although many agency officials are reluctant to give up their proximity to power, a move to the suburbs appeared to be the only way to obtain badly needed additional space and modern administrative conveniences. As with every federal agency, NSF must do as it is told by the government's landlord, the General Services Administration.

However, two states - Maryland and Virginia - surround Washington, and each wanted the agency as a tenant. After a long fight between politicians from both states, Virginia won and in 1990 the government signed an agreement to occupy a 450,000 square-foot-facility in the Virginia suburb of Ballston in 1993. In addition to an atrium, the building features conference rooms and space for large meetings.

Maryland, however, never gave up, and NSF officials made it clear that they wanted to remain downtown. Earlier this month, Senator Barbara Mikulski (Democrat, Maryland), the chairwoman of the appropriations committee that funds NSF, stripped from the agency's 1993 budget an amount roughly equal to the $\$ 16$ million that NSF intended to spend next year to move. The House bill explicitly removes any money for a move.

Concerned that politics - rather than NSF's interests - may be becoming the focus of the debate, Representative Howard Wolpe (Democrat, Michigan) chairman of the investigations subcommittee of the House science committee, asked the congressional General Accounting Office (GAO) in June to weigh the pros and cons of the move and to investigate the way in which decisions have been reached. But now even that probe is feeling the political heat. Virginia's two senators have asked GAO to rush the report and write up its findings in a letter rather than the usual more comprehensive report.

NSF, meanwhile, is lying low. Walter Massey, the agency's director, said last week that plans are in abeyance, pending the completion of the GAO investigation.

Christopher Anderson 